\title{
Daniel Gerbaulet
}

\section{Der Unternehmer als Reputator}

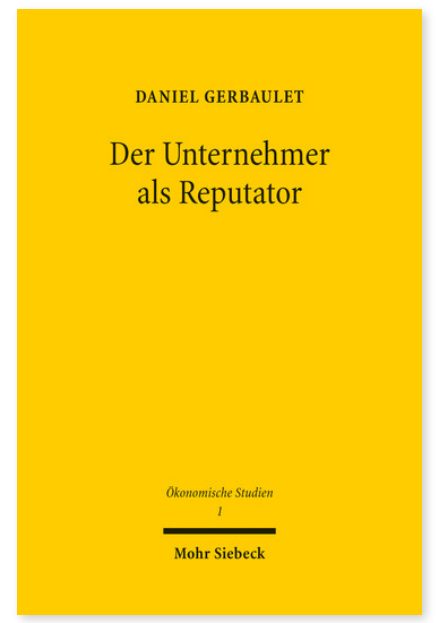

2016. XII, 194 Seiten. ÖkonSt 1

ISBN 978-3-16-154957-1

DOI 10.1628/978-3-16-154957-1

eBook PDF 69,00€

ISBN 978-3-16-154936-6

fadengeheftete Broschur $69,00 €$
Aufbau und Pflege der aus ehrbarer unternehmerischer Tätigkeit entstehenden Reputation und im Besonderen deren aktive unternehmerische Verwendung und Vermarktung determinieren und kennzeichnen den als »Reputator « handelnden Unternehmer. Ziele dieser neuen dynamischen Unternehmerfunktion sind der Abbau von Unsicherheiten,

Informationsasymmetrien und Transaktionskosten, die Förderung von Kooperationen sowie die Generierung strategischer Wettbewerbsvorteile.

Die theoretische Unternehmerforschung und die ihr zugehörige, mit den Namen großer Nationalökonomen verbundene Grundlagenforschung wies den Unternehmer bis dato primär als Träger der Ungewißheit (Knight), als Innovator (Schumpeter), als Arbitrageur (Kirzner) und als Koordinator (Casson) aus. Daniel Gerbaulet zeigt, dass die bestehende Unternehmertheorie durch den neugeschaffenen Reputator um eine zeitgemäße, den Begebenheiten des Informationszeitalters Rechnung tragende dynamische Unternehmerfunktion ergänzt, damit grundlegend erweitert und so in das 21. Jahrhundert hinein fortgeschrieben werden kann.

Daniel Gerbaulet Geboren 1985; Studium der Wirtschaftswissenschaft an der Ruhr-Universität Bochum; seit 2012 Wissenschaftlicher Mitarbeiter am Lehrstuhl für Betriebswirtschaftslehre, insbesondere Investitionstheorie und Unternehmensbewertung an der Fern-Universität in Hagen; 2016 Promotion.

Jetzt bestellen:

https://mohrsiebeck.com/buch/der-unternehmer-als-reputator-9783161549571?no_cache=1 order@mohrsiebeck.com

Telefon: $+49(0) 7071-923-17$

Telefax: $+49(0) 7071-51104$ 